\title{
Oxidation of Hemoglobin F Is Associated with the Aging Process of Neonatal Red Blood Cells
}

\author{
R. ADVANI, W. MENTZER, D. ANDREWS, AND S. SCHRIER \\ Division of Hematology, Department of Medicine, Stanford University School of Medicine, Stanford, California \\ 94305 [R.A., S.S.] and Department of Pediatrics, University of California at San Francisco, \\ San Francisco, California 94143 [W.M., D.A.]
}

\begin{abstract}
Previously, we reported that in cord blood there is a population of very dense, surface area-depleted red blood cells $(\mathrm{RBC})$. We hypothesized that oxidative damage might account for the generation of this cell population because $\mathrm{Hb} \mathrm{F}$ is known to be mildly unstable in vitro. Accordingly, we examined density-separated subpopulations of neonatal red cells searching for evidence of oxidant injury to $\mathrm{Hb}$ in vivo. Cord or adult $\mathrm{RBC}$ were separated into populations of varying density and an increased amount of membrane-associated globin was found in the densest fraction of cord RBC. Solubilized ghosts from each fraction were analyzed by thiol-disulfide exchange chromatography for the presence of oxidized $\mathrm{Hb}$ and spectrophotometrically for the presence of membranebound hemichrome. About four times more oxidized $\mathbf{H b}$ was found in unseparated cord RBC than in adult RBC. This difference was most evident in the densest 10-15\% RBC subfractions. Membrane-bound hemichrome levels in cord cells were twice those found in adult cells. We found that in cord membrane skeletons there was 2.5 to 9 times as much globin in the dense fraction as compared to the light fraction. Membrane skeletons from dense and light adult $\mathrm{RBC}$ differed little from one another. We postulate that membrane (and perhaps membrane skeleton)-associated oxidized $\mathrm{Hb}$ is a marker for more generalized oxidative damage, which may create the population of unusually dense cells found in cord blood and ultimately shorten their life span. (Pediatr Res 32: 165-168, 1992)
\end{abstract}

\section{Abbreviations}

RBC, red blood cell

PMSF, phenyl methyl sulfonyl fluoride

The life span of neonatal red cells is less than that of adult cells (1). In accordance with their younger mean cell age, a higher proportion of neonatal than adult red cells separate into the lightest fractions after identical density gradient centrifugation (2). In addition, a small number of neonatal cells are more dense than the densest adult red cells when separated in a discontinuous Stractan gradient (2). These have a higher percentage of $\mathrm{Hb} \mathrm{F}$ than the lighter cells (3) and represent relatively old cells formed earlier in gestation. Increased amounts of membrane-associated globin are found in this fraction (4). The cause of the reduced life span of neonatal red cells is not known, and various etiologies have been proposed such as loss of plasma membrane surface

Received May 22, 1991; accepted March 12, 1992.

Correspondence and reprint requests: Stanley L. Schrier, M.D., Division of Hematology, S161, Department of Medicine, Stanford University Medical Center, Stanford, CA 94305.

Supported by a grant from USPHS (DK 32094). area, altered protein-lipid or protein-protein interactions, and free radical damage (2). $\mathrm{Hb} \mathrm{F}$ is known to be mildly unstable in vitro (5) and neonatal red cells are known to have diminished activity of methemoglobin reductase, glutathione peroxidase, and catalase, which increases susceptibility to oxidants $(6,7)$. We hypothesized that the membrane-associated globin might cause oxidative damage by action of the associated heme or hemichromes or by iron acting as a Fenton reagent (8), thus accounting for the generation of this dense population. Accordingly, we examined density-separated subpopulations of neonatal and adult red cells, analyzed the $\mathrm{RBC}$ membrane skeleton to quantify the globin chains present, and used thiol-disulfide exchange chromatography to look for evidence of oxidative attack (9).

\section{MATERIALS AND METHODS}

SDS was obtained from BHD Ltd., Poole, England. Diisopropyl fluorophosphate, leupeptin, pepstatin, PMSF, and Triton X 100 were obtained from Sigma Chemical Co., St. Louis, MO. $\beta$ Mercaptoethanol was obtained from Bio-Rad Laboratories, Richmond, CA. Thiol-activated sepharose 4B was obtained from Pharmacia Fine Chemicals, Uppsala, Sweden.

All blood samples were drawn according to methods approved by the Stanford University Institutional Review Board and the UCSF Committee on Human Research.

Neonatal blood was collected by venipuncture from fetal placental vessels 5 to 30 min after delivery of the placenta. Adult and neonatal samples were anticoagulated in acid citrate dextrose and immediately filtered through $\alpha$-cellulose/Sigmacell (Sigma Chemical Co.) to remove leukocytes (10). The red cells were then washed twice in isotonic buffered saline potassium glucose, centrifuged at $2500 \mathrm{rpm}$ for $10 \mathrm{~min}$ and the supernatant buffered saline potassium glucose removed. A modification of the method described by Murphy (11) was then used to separate red cell fractions according to buoyant density. Packed red cells were centrifuged for $1 \mathrm{~h}$ at $30^{\circ} \mathrm{C}$ in an angle head rotor (Sorvall RC5 B centrifuge) and then for $30 \mathrm{~min}$ at $30000 \mathrm{rpm}$ at $4^{\circ} \mathrm{C}$ in a swinging bucket rotor (Beckman ultracentrifuge). Samples representing approximately $10-15 \%$ of the red cell population were harvested from the top, middle, and bottom of the centrifuged column of red cells using a tube slicer. The RBC were then washed with PBS, pH 7.4. Ghosts were prepared by hypotonic lysis as previously described using $5 \mathrm{mM}$ phosphate buffer, $\mathrm{pH}$ 8.0, containing $100 \mathrm{mg} / \mathrm{L}$ of PMSF and $0.1 \mathrm{mM}$ EDTA (9). Triton extracted skeletons were prepared from ghosts as previously described (12). Protein composition of membranes and skeletons was determined by SDS-PAGE using 6-18\% gradient gels that were stained with Coomassie blue (13). These and all other gels were scanned using an LKB ultrascan XL laser densitometer (no. 2222-420; Bromma, Sweden).

Ghosts were examined for evidence of protein oxidation using thiol-activated chromatography (9). This method is based on the principle that proteins that contain reduced thiols will bind to 
the thiol-activated sepharose gel. Those proteins appearing in the unbound filtrate either have no free thiols or their thiols have been blocked or converted into disulfide, presumably by oxidative processes. Proteins with free thiols that were bound to the thiol-activated sepharose were eluted by addition of $\beta$-mercaptoethanol (9). Because we were using this method in a quantitative manner, it was critical to be sure that we never overloaded the thiol-sepharose columns. Therefore, rather than adding the customary $5 \mathrm{mg}$ of membrane protein per column, we kept our additions within the range of $2.5-3.0 \mathrm{mg}$ protein per column. PMSF $100 \mathrm{mg} / \mathrm{mL}$ and $0.1 \mathrm{mM}$ EDTA were used as protease inhibitors during all steps of this procedure (9).

Samples were dialyzed, concentrated, and analyzed by SDSPAGE and Coomassie blue. It is known that in normal human RBC membranes only two proteins, glycophorin A and Protein 7 , appear in the unbound filtrate because these proteins natively have no free thiols. Because it is not always possible to process identical numbers of red cells, the amount of each sort of band appearing in the unbound filtrate was normalized to the Protein 7 content as measured by laser densitometry of the Coomassie blue-stained gels. Western blotting using an affinity purified anti$\mathrm{Hb}$ was done as described (14).

In providing an index of globin remaining in the bound fraction of thiol disulfide exchange chromatography (nonoxidized fraction), we related the globin content to the content of membrane actin, a very stable component of the membrane skeleton.

Membrane-bound hemichromes were assessed as described by Asakura et al. (15).

\section{RESULTS}

Membrane-bound $\mathrm{Hb}$. Ghosts from density-separated cord or adult red cells were solubilized in SDS and then subjected to thiol-disulfide exchange chromatography and the unbound "sulfhydryl free" fractions were analyzed by SDS-PAGE (Figs. 1 and 2). Gel analysis revealed a protein with the electrophoretic mobility of globin to be more abundant in cord red cells than in adult cells. The identity of this band as globin was confirmed by Western blotting using an affinity purified antibody to $\mathrm{Hb}$ (data

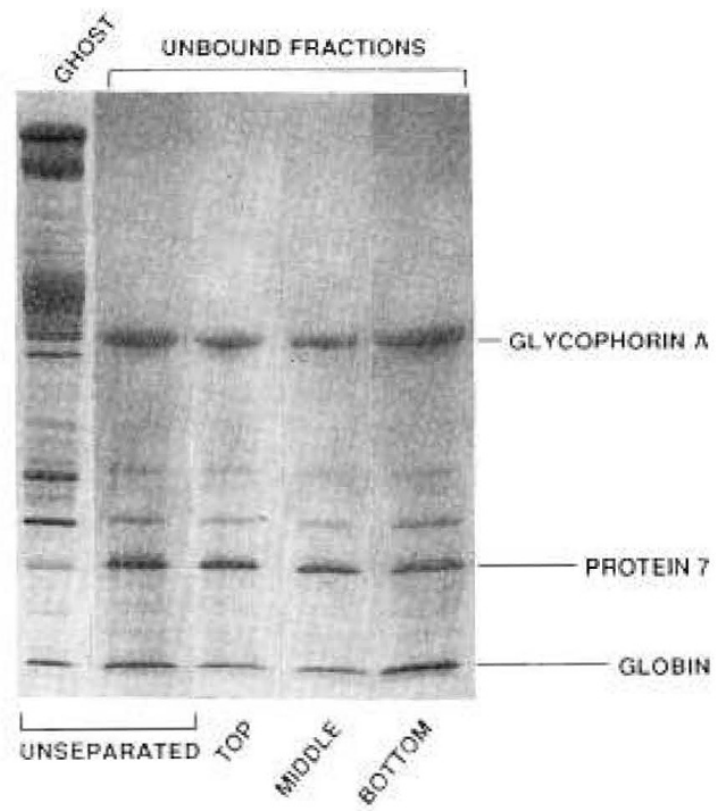

Fig. 1. Oxidized globin associated with cord red cell membranes. Membranes prepared from unseparated or density-separated cord red cells were subjected to thiol-disulfide exchange chromatography. Unbound (oxidized) fractions were analyzed by $6-18 \%$ SDS-PAGE. Red cell ghosts not subjected to thiol-disulfide chromatography were also run to identify the position of various red cell proteins of interest (left lane).

\section{UNBOUND FRACTIONS}

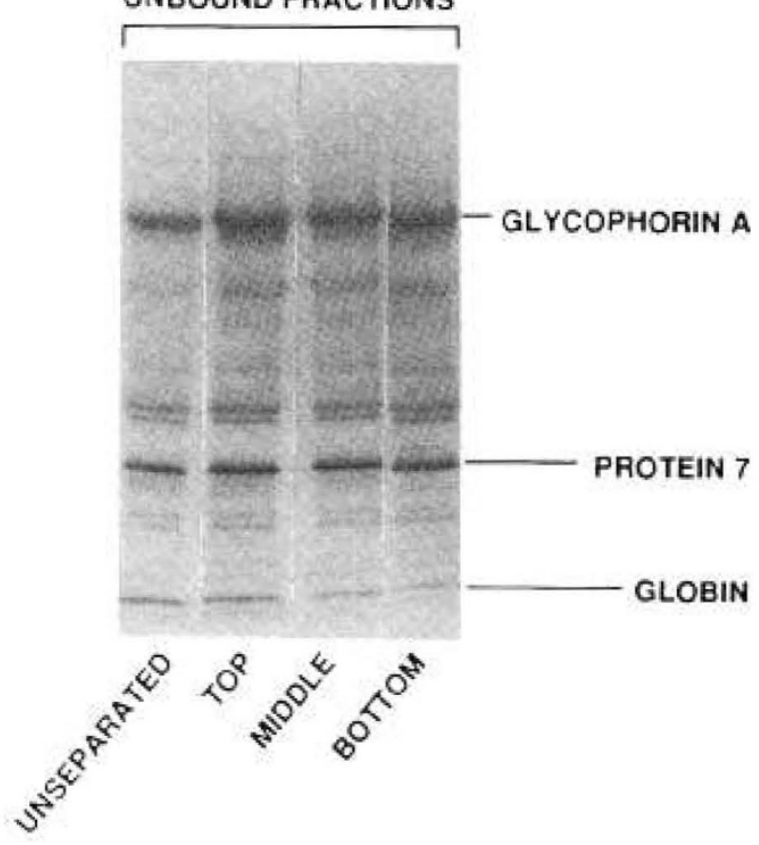

Fig. 2. Oxidized globin associated with adult red cell membranes. Membranes prepared from unseparated or density-separated adult red cells were subjected to thiol-disulfide exchange chromatography. Unbound (oxidized) fractions were analyzed by $6-18 \%$ SDS-PAGE.

Table 1. Oxidized globin/Protein 7

\begin{tabular}{cccll}
\hline & Unseparated & Top & Middle & Bottom \\
\hline Cord blood & & & & \\
1 & 0.60 & 0.56 & 0.625 & 1.8 \\
2 & 1.19 & 0.42 & 0.53 & 1.44 \\
3 & 0.99 & 0.85 & 1.21 & 2.03 \\
4 & 0.83 & 0.46 & 0.76 & 2.51 \\
Adult & & & & \\
1 & 0.198 & 0.326 & 0.256 & 0.53 \\
2 & 0.17 & 0.295 & 0.326 & 0.45 \\
\hline
\end{tabular}

Table 2. Relative globin content of ghosts

\begin{tabular}{llll}
\hline & Top & Middle & Bottom \\
\hline Cord blood & & & \\
$\quad$ Unbound fraction (oxidized)* & 0.46 & 0.76 & 2.51 \\
$\quad$ Bound fraction $\dagger$ & 0.507 & 0.580 & 1.472 \\
Adult blood & & & \\
$\quad$ Unbound fraction (oxidized)* & 0.103 & 0.174 & 0.74 \\
$\quad$ Bound fraction $\dagger$ & 0.258 & 0.584 & 1.602 \\
\hline
\end{tabular}

* Globin content expressed as the globin/Protein 7 ratio.

$\uparrow$ Globin content expressed as the globin/actin ratio.

not shown). Densitometric scanning (Table 1) of the gels indicated that about four times as much $\mathrm{Hb}$ was present in the oxidized fraction of unseparated cord cells as in adult cells. The difference was the least in the top subfraction and was most evident in the densest $10-15 \%$ RBC subfraction.

The question that then arose was whether the oxidized fraction of membrane globin was a constant fraction of membrane globin in cord and adult RBC. This was analyzed by comparing the relative amounts of oxidized globin appearing in the unbound fraction with the relative amounts of globin that were retained in the bound fraction of ghost proteins because they contained free sulfhydryl groups. A single representative paired experiment of adult and cord RBC separated by density is shown in Table 2. It appears that the relative amounts of both oxidized and native globin increase in parallel as a consequence of density in cord and adult RBC. However, the absolute amount of oxidized 
globin is always greater in cord RBC in all density-defined fractions.

Cytoskeletons were prepared from cord and adult ghosts after each density separation of red cells and evaluated for the presence of globin (Fig. 3). Cord blood membrane skeletons had 2.5-9 (average 4.9) times as much globin in the dense fraction as in the light fraction. In contrast, a more modest increase (1.8-1.9 times) in globin was noted in dense compared to light adult red cell cytoskeletons.

Membrane-bound hemichrome. Membrane-bound hemichrome was assessed in six cord red cell samples and four adult samples. Eleven samples from patients with sickle cell anemia and two from other unstable hemoglobinopathies ( $\mathrm{Hb}$ Hasharon, $n=1$, and $\mathrm{Hb} \mathrm{H}$ disease, $n=1$ ) were also assessed for comparative analysis (Table 3 ).

Although more membrane-bound hemichrome was found in cord red cells than in adult cells, it did not reach the levels seen in sickle cell anemia or unstable hemoglobinopathies. In four density-separated adult red cell samples, there was little difference between light and dense fractions $(0.0113 \pm 0.006 \%$ versus $0.0143 \pm 0.007 \%$ ). A greater increase in dense relative to light fraction hemichrome was noted in cord red cells $(0.025 \pm 0.012 \%$ versus $0.042 \pm 0.03 \%$ ), but again these values were well below those found in sickle cell anemia or unstable hemoglobinopathies.

\section{DISCUSSION}

Various studies have described abnormal association of free heme or $\mathrm{Hb}$ with the membrane in sickling disorders (16), in unstable $\mathrm{Hb} \mathrm{H}$ disease (17), and in $\beta$-thalassemia (18). The deleterious effects caused by these agents, some of which are mediated by oxidation (19), have been postulated to attenuate RBC survival.

It is our hypothesis that one cause of the reduced life span of neonatal red cells may be membrane oxidative damage. In support of this possibility, when ghosts from the densest layers

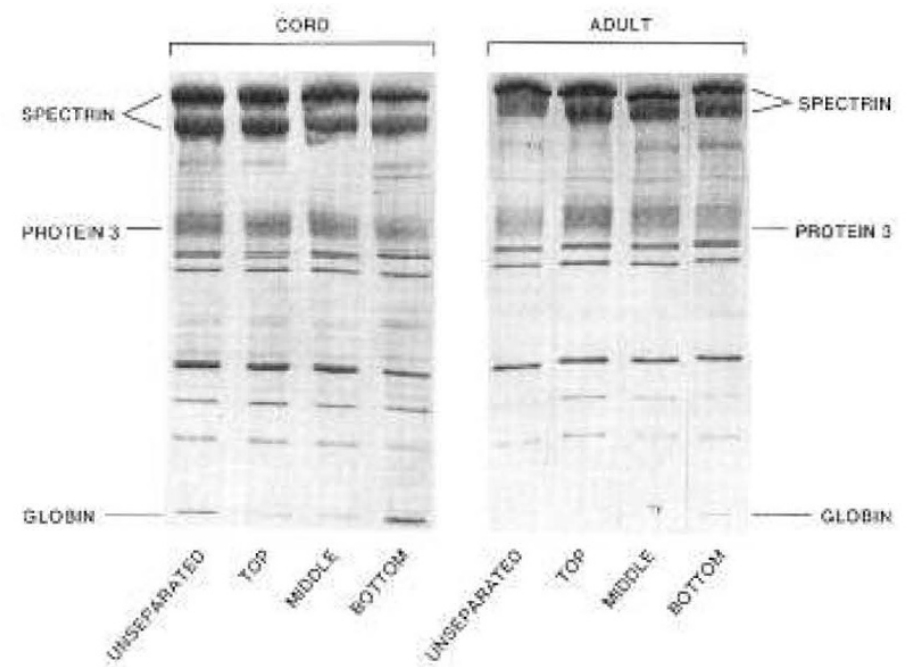

Fig. 3. Membrane cytoskeleton-associated globin in cord and adult red cells. Membrane proteins from unseparated or density-separated red cells were analyzed by SDS-PAGE (6-18\% acrylamide).

Table 3. RBC membrane hemichrome (\%)

\begin{tabular}{lrlc}
\hline & Number & Mean \pm SD & Range \\
\hline Adult & 4 & $0.012 \pm 0.005$ & $0.008-0.019$ \\
Cord & 6 & $0.025 \pm 0.01$ & $0.017-0.037$ \\
Sickle cell anemia & 11 & $0.081 \pm 0.024$ & $0.054-0.114$ \\
Unstable hemoglobinopathies & 2 & 0.155 & $0.045^{*}-0.264 \dagger$ \\
\hline
\end{tabular}

* Hb Hasharon $(n=1)$

$\dagger \mathrm{Hb} \mathrm{H}(n=1)$. of adult and neonatal $\mathrm{RBC}$ were examined for evidence of protein oxidation using thiol-disulfide exchange chromatography, there was evidence of increased content of oxidized globin in the densest population of cord cells compared to adult cells (Figs. 1 and 2, Table 1). We then studied the relative amounts of globin in the bound fraction of thiol disulfide exchange chromatography and noted that there was a density-dependent increase in nonoxidized globin (Table 2), which was similar in relative terms in adult and cord RBC. This could mean that the oxidized fraction represents a relatively constant fraction of total ghost globin. When we examined density-separated cord red cell cytoskeletal fractions, we found that the densest cord fractions had more globin than the light fractions, whereas adult RBC fractions differed little (Fig. 3). We interpret these results to mean that although the content of oxidized globin in ghosts may represent a constant fraction of total membrane-bound globin the absolute amount of oxidized globin is greatly increased in dense cord $\mathrm{RBC}$ and that the amount of oxidized globin bound to the skeleton of these RBC is also greatly increased.

Increased membrane-associated oxidized globin has also been found in the thalassemias (20) and sickle cell disease (9). In the thalassemias, membrane-bound globin is approximately 40 times greater than in control $(20)$ and is associated with decreased deformability of red cells. A similar change in mechanical property has also been noted when normal red cells are treated in vitro with an oxidizing agent such as phenylhydrazine (21). Thioldisulfide analysis of these ghosts has also shown evidence of increased oxidized globin $(20,21)$.

In an analogous way, it is possible that the increased oxidized globin found in the densest layer of cord cells may be responsible for altering the cytoskeletal function. These dense RBC have been shown to be far less deformable than any other subpopulation of either neonatal or adult red cells (22). Although at least some of this reduction is due to loss of surface area, an adverse effect on membrane deformability may conceivably be present as well. The extent of oxidation is difficult to assess; the thioldisulfide column chromatography method underestimates oxidative attack because it identifies only complete loss of all free sulfhydryls, primarily cysteine residues, whereas other amino acids such as tyrosine, methionine, and histidines are also subject to oxidative attack (23).

Evaluation of membrane-bound hemichromes revealed a modest increase in dense cord $\mathrm{RBC}$, and values tended to parallel the increases in oxidized globin (Tables 1 and 2). Both oxidized globin and hemichromes are also found in much larger quantities in severe thalassemia (18) and sickle cell anemia (9), diseases in which other cytoskeletal proteins are also noted to have been oxidized $(9,20)$.

Our studies indicate that there is accumulation of oxidized globin and hemichromes on the membranes and on the skeletons of more dense and therefore possibly older cord red cells. Whether this reflects prolonged or increased exposure to oxidant attack in vivo, impaired antioxidant capabilities, enhanced susceptibility of $\mathrm{Hb} \mathrm{F}$ to oxidation, or a combination of more than one of these factors is unclear.

This increase in membrane-associated oxidized globin may be responsible for altered cellular properties including increased rigidity and cell density. Further studies, however, will be needed to fully establish the role of oxidized globin in the shortening of cord RBC life span.

\section{REFERENCES}

1. Pearson HA 1967 Life span of the fetal red blood cell. J Pediatr 70:166-171

2. Matovick L, Mentzer W 1985 The neonatal red cell membrane. In: Schrier SL (ed) Clinics in Hematology. WB Saunders, London, pp 203-221

3. Gahr M, Meves H, Schroter W 1979 Fetal properties in red blood cells of newborn infants. Pediatr Res 13:1231-1236

4. Lane PA, Galili U, Larocci TA, Shew RL, Mentzer WC 1988 Cellular dehydration and immunoglobin binding in senescent neonatal erythrocytes. Pediatr Res 23:288-292

5. Smith WB, Fujimura S, Lubin B, Bradley T 1976 Unstable properties of fetal hemoglobin. Pediatr Res 10:483a(abstr) 
6. Gross S 1976 Hemolytic anemia in premature infants: relationship to vitamin E, selenium, glutathione peroxidase and erythrocyte lipids. Semin Hematol 13:187-199

7. Gross S 1978 Antioxidant relationship between selenium dependent glutathione peroxidase and tocopherol. Am J Pediatr Hematol Oncol 1:61-69

8. Hebbel RP 1985 Auto-oxidation and a membrane-associated "Fenton Reagent." A possible explanation for development of membrane lesion in sickle erythrocytes. In: Schrier SL (ed) Clinics in Hematology. WB Saunders, London, pp 129-140

9. Rank B, Carlsson J, Hebbel R 1985 Abnormal redox status of membrane protein thiols in sickle erythrocyte. J Clin Invest 75:1531-1537

10. Beutler E 1975 Red Cell Metabolism: A Manual of Biochemical Methods, 2nd Ed. Grune and Stratton, New York

11. Murphy JR 1973 Influence of temperature and method of centrifugation on the separation of erythrocytes. J Lab Clin Med 82:334-341

12. Yu J, Fishman D, Steck T 1973 Selective solubilization of proteins and phospholipids from red blood cell membranes by non-ionic detergents. J Supramol Struct 1:233-248

13. Schrier S, Junga I, Ma L 1986 Endo and exovesiculation and the structure of the human red cell membrane. J Lab Clin Med 108:265-271

14. Shinar E, Shalev 0, Rachmilewitz EA, Schrier SL 1987 Erythrocyte membrane skeleton abnormalities in severe beta thalassemia. Blood 70:158-164
15. Asakura T, Minakata K, Adachi K, Russell MO, Schwartz E 1977 Denatured hemoglobin in sickle erythrocytes. J Clin Invest 59:633-640

16. Hebbel RP, Eaton JW, Balasingam H 1982 Spontaneous oxygen radical generation by sickle erythrocytes. J Clin Invest 70:1253-1259

17. Flynn TP, Allen DW, Johnson GJ, White JG 1983 Oxidant damage of the lipids and proteins of the erythrocyte membranes in unstable hemoglobin disease: evidence for the role of lipid peroxidation. J Clin Invest 71:12151223

18. Rachmilewitz EA, Shinar E, Shalev 0, Galili U, Schrier SL 1985 Erythrocyte membrane alterations in $\beta$ thalassemia. Clin Hematol 14:163-182

19. Hebbel RP, Eaton JW 1989 Pathobiology of heme interaction with the erythrocyte membrane. Semin Hematol 26(suppl 2):136-149

20. Advani R, Sorenson S, Shinar E, Lande W, Rachmilewitz EA, Schrier S 1992 Characterization and comparison of the $\mathrm{RBC}$ membrane damage in severe human alpha and beta thalassemia. Blood 79:1058-1063

21. Schrier SL, Ma L, Mohandas N 1992 Globin chain specificity of oxidationinduced changes in red blood cell membrane properties. Blood 79:15861592

22. Matovick L, Chiu D, Lubin B, Mentzer WC, Mohandas N, Schrier SL 1986 The aging process of human neonatal erythrocytes. Pediatr Res 20:10911096

23. Schwartz RS, Rybicki AC, Nagel RL 1989 Oxidation of membrane proteins increases with cell density in normal and sickle red cells. Blood 74(suppl 1): $183 \mathrm{a}(\mathrm{abstr})$ 